\title{
AVALIAÇÃO DO IMPACTO NA APLICAÇÃO DE UM PROTOCOLO DE ATENDIMENTO CIRÚRGICO
}

Autores: Karen Kato Botelho / Adriana Araujo dos Santos
Instituição: Hospital Villa-Lobos / Rede D’ Or São Luiz

\section{Introdução}

A Organização Mundial de Saúde define como idoso todo indivíduo com idade igual ou superior a 60 anos. Atualmente, essa classe populacional vem apresentando acentuado crescimento, prevalecendo o surgimento de doenças crônicos degenerativas contribuindo para a ocorrência de fraturas estimando o surgimento de 4,5 milhões de novos casos até 2050. Desta maneira, a gestão destes pacientes torna-se cada vez mais importante considerando as comorbidades visto a exposição aos riscos em ambiente hospitalar.

\section{Resultados}

Após a implantação da linha de cuidado multidisciplinar, verificamos o tempo médio de 1 dia para a abordagem cirúrgica, com redução considerável do tempo médio de internação hospitalar para 7,7 dias entre o diagnóstico, cirurgia e alta hospitalar.

Tempo Abordagem Cirúrgica (média)

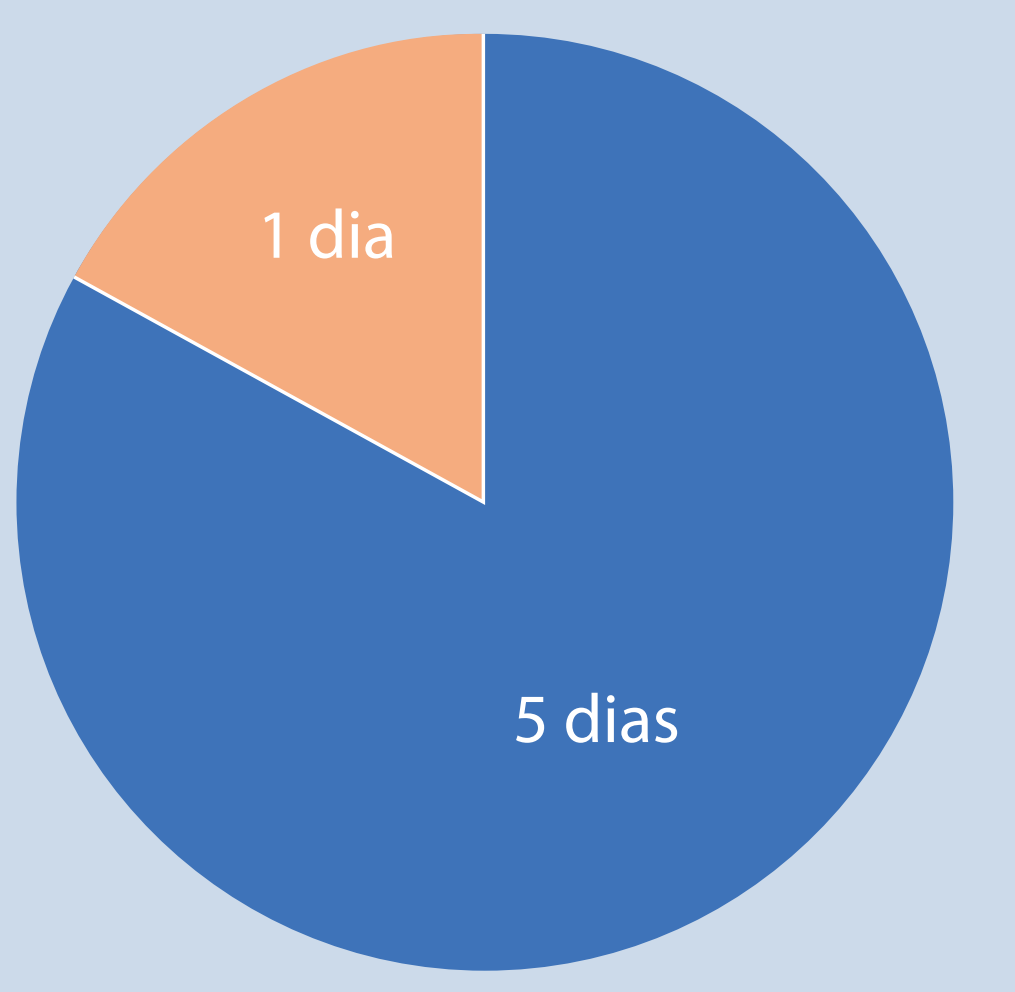

Legenda:

Tempo médio de Abordagem Cirúrgica antes do Protocolo Tempo médio de Abordagem Cirúrgica Após o Protocolo
Tempo Internação Hospitalar (média)

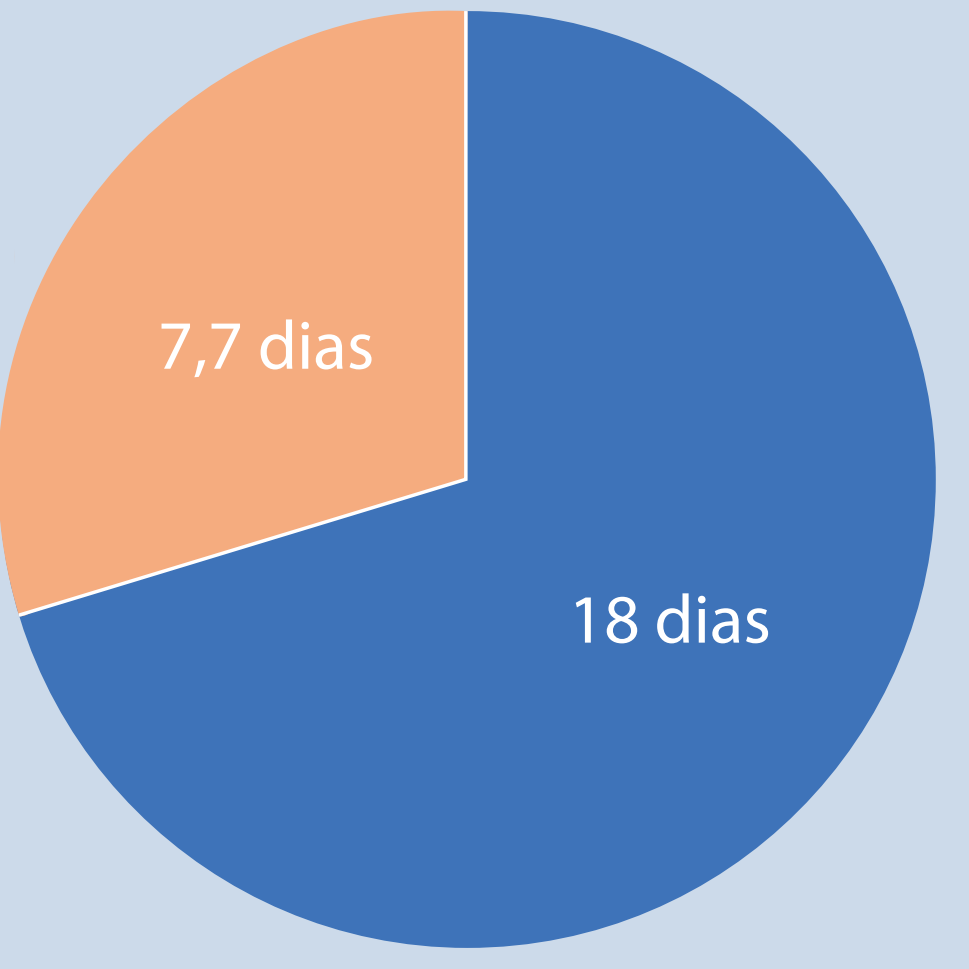

Tempo médio de Internação Hospitalar antes do Protocolo Tempo médio de Internação Hospitalar Após o Protocolo

\section{Objetivo}

Avaliar o impacto da implantação de um protocolo de atendimento a pacientes com fraturas de fêmur.

\section{Método}

Trata-se de um estudo de caso/relato de experiência, avaliando 18 casos tratados cirurgicamente de fratura de fêmur no período de janeiro a dezembro de 2017 em um hospital privado da cidade de São Paulo. Foi elaborado um protocolo de atendimento multidisciplinar, segmentado em cinco dias compreendendo o período do diagnóstico até a alta hospitalar, descrevendo neste processo, os pontos de atuação de cada membro da equipe.

\section{Conclusão.}

O impacto da aplicação de um protocolo de atendimento a pacientes com fratura de fêmur traz resultados positivos, de acordo com o estudo realizado, diminuindo o tempo para abordagem cirúrgica e o tempo de internação hospitalar.

PLANO TERAPÊUTICO - ATENDIMENTO CIRÚRGICO FRATURAS DE FÊMUR

\begin{tabular}{|c|c|c|c|c|c|}
\hline & D 1 & D 2 & D 3 & D 4 & D 5 \\
\hline ORTOPEDISTA & 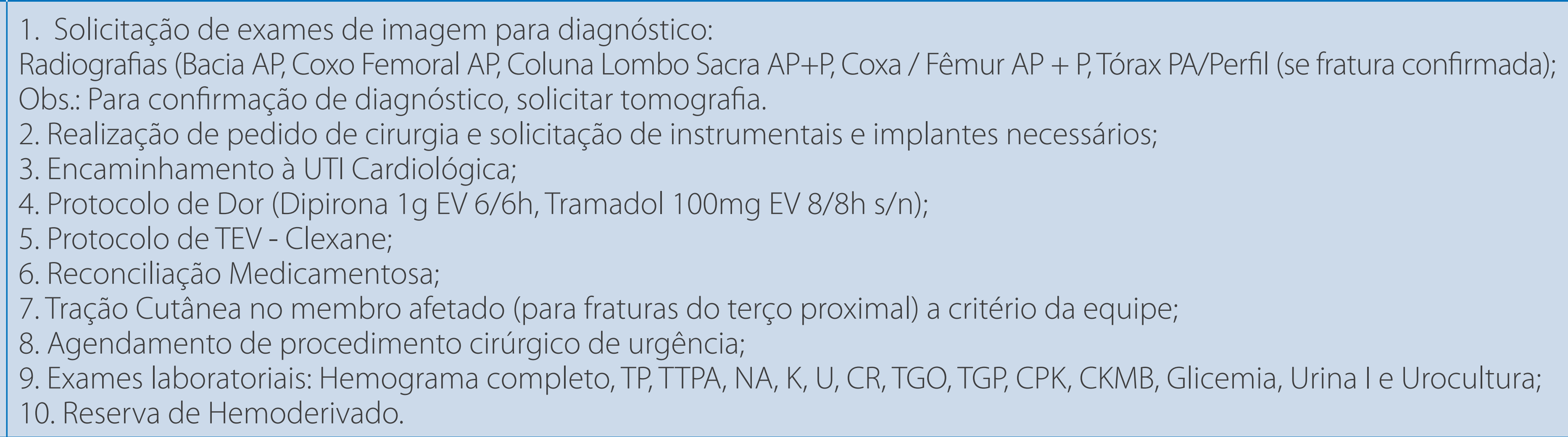 & $\begin{array}{l}\text { 1. Cirurgia Precoce (realização em até } 24 \text { horas); } \\
\text { 2. Orientação ao paciente familiares sobre } \\
\text { procedimento cirúrgico, riscos e previsão do tempo de } \\
\text { internação (aoplicaçăo do termo de consentimento); } \\
\text { 3. Confirmaçăo material especial; } \\
\text { 4. Protocolo Cirurgia Segura (Demarcação Sítio). }\end{array}$ & $\begin{array}{l}\text { 1. Avaliar suspeita de } \\
\text { Trombose; } \\
\text { 2. Suspensão } \\
\text { antibióticoprofilático. }\end{array}$ & $\begin{array}{l}\text { 1.Avaliação } \\
\text { ortopédica; } \\
\text { 2. Avaliar critérios } \\
\text { de Alta Hospitalar. }\end{array}$ & $\begin{array}{l}\text { 1. Alta Hospitalar; } \\
\text { 2. Plano de Alta. }\end{array}$ \\
\hline UTI CARDIOLÓGICA & $\begin{array}{l}\text { 1. Avaliação Cardiológica: ECG de repouso, *Ecocardiograma com doppler colorido (Recomendado); } \\
\text { 2. Controle Glicêmico; } \\
\text { 3. Protocolo Delirium. }\end{array}$ & $\begin{array}{l}\text { Cuidado Padrão: evitar hipotensão, } \\
\text { evitar e corrigir sangramento excessivo, manter } \\
\text { betabloqueado se não houver contraindicaçẫo. }\end{array}$ & $\begin{array}{l}\text { 1. Critérios de alta } \\
\text { para unidade de } \\
\text { internaçãa; }\end{array}$ & & \\
\hline NUTRIÇÃo & $\begin{array}{l}\text { 1. Avaliação Nutricional; } \\
\text { 2. Protocolo Abreviação de jejum se cirurgia D2 período da manhã. }\end{array}$ & $\begin{array}{l}\text { 1. Jejum } \\
\text { 2. Monitoramento jejum (protocolo abreviação de jejum). }\end{array}$ & & & \\
\hline ENFERMAGEM & $\begin{array}{l}\text { 1. Triagem do paciente; } \\
\text { 2. Monitorização cardíaca; } \\
\text { 3. Encaminhamento do paciente à UTI; } \\
\text { 4. Protocolo de queda; } \\
\text { 5. Protocolo prevenção de úlcera de pressão. }\end{array}$ & $\begin{array}{l}\text { 1. Preparo do paciente pré-operatório: } \\
\text { Banho e tricotomia } 2 \mathrm{~h} \text { antes do procedimento cirúrgico; } \\
\text { 2. Prevenção de lesão de pele. }\end{array}$ & & $\begin{array}{l}\text { Admissão Unidade } \\
\text { de Internação } \\
\text { Protocolo Curativo }\end{array}$ & $\begin{array}{l}\text { 1. Orientação de } \\
\text { Alta Hospitalar; } \\
\text { 2. Acompanhar } \\
\text { Alta Hospitalar. }\end{array}$ \\
\hline FISIOTERAPIA & $\begin{array}{l}\text { Protocolo } \\
\text { Fisioterapia. }\end{array}$ & & \begin{tabular}{|l|l|} 
Protocolo \\
Fisioterapia.
\end{tabular} & \begin{tabular}{|l|l|} 
Protocolo \\
Fisioterapia.
\end{tabular} & \begin{tabular}{|l|l|} 
Protocolo \\
Fisioterapia.
\end{tabular} \\
\hline ANESTESIOLOGIA & & $\begin{array}{l}\text { 1. Avaliação pré-anestésica; } \\
\text { 2. Protocolo de Hipotermia; } \\
\text { 3. Protocolo Antibioticoprofilaxia. }\end{array}$ & & & \\
\hline CENTRO CIRÚRGICO & Comunicação de Procedimento Cirúrgico de Urgência. & $\begin{array}{l}\text { 1. Preparo de materiais e instrumentais; } \\
\text { 2. Montagem de Sala Operatória. }\end{array}$ & & & \\
\hline FARMÁCIA & $\begin{array}{l}\text { 1. Acompanhamento Reconciliação Medicamentosa; } \\
\text { 2. Monitoramento interação Droga x Nutriente. }\end{array}$ & & & & \\
\hline
\end{tabular}

\section{Referências}

1. Franco LG, Kindermann AL, Tramujas L, Kock KS. Fatores associados à mortalidade em idosos hospitalizados por fraturas de fêmur. Rev. bras. ortop. 2016 Set./Out; 51(5):509-514.

2. Felicissimo P, Branco J. Percurso clínico e programa de alta nos doentes com fratura da extremidade proximal do fêmur. Rev Port Ortop Traum. 2017; vol 25(4): 303-310. 3. Imbelloni LE, Teixeira DMP, Coelho MT, Gomes D, Braga RL, Filho GBM, Silva A. Avaliação dos resultados da implantação de um protocolo de cuidados perioperatórios em pacientes submetidos à cirurgia ortopédica Rev. Col. Bras. Cir. 2014; 41(3):161-167. 